\title{
Türkiye Bölgesel Sayısal Bölünme Düzeylerinin Belirlenmesinde Gini Yaklaşımı
}

\begin{abstract}
Hüseyin Fidan ${ }^{\mathrm{a}}$
Öz: Birçok avantaj sağlayan bilişim teknolojileri, kullanım farklılılarına bağlı olarak bazı sorunları da beraberinde getirmektedir. Bilişim teknolojilerini kullanabilen ve kullanamayanlar arasında oluşan farklılıklar, eşitsizliklere sebep olmaktadır. Sayısal uçurum veya sayısal bölünme olarak ifade edilen bu farklılıklar, teknolojideki gelişmelerle birlikte derinleşmekte ve sebep olduğu eşitsizlik düzeylerinin belirlenmesi önem kazanmaktadır. Sayısal bölünme düzeylerinin belirlenmesinde genellikle bilgisayar ve internet kullanım oranları gösterge olarak kullanılmakta, analizler demografik değişkenlere göre istatistiksel yöntemlerle yapılmaktadır. Eşitsizliklerin ölçülmesinde standart araçlardan olan Gini yöntemi, sayısal bölünme çalışmalarında nadiren kullanılmıştır. Türkiye'de ise Gini katsayılarını kullanarak sayısal bölünme düzeyinin belirlenmesine yönelik çalışma bulunmamaktadır. Bu çalışmada Türkiye'de yaşayan kişilerin bilgisayar ve internet kullanım düzeyleri arasındaki farklııklar Gini katsayıları ile belirlenmiştir. Söz konusu farklııkların belirlenmesi için veriler, Türkiye istatistik Kurumu (TÜiK) Hanehalkı Bilişim Teknolojileri Kullanım Araştırması'nda yer alan Düzey1 bölgeleri için bilgisayar ve internet kullanım oranlarını içeren raporlardan elde edilmiştir. Araştırmada bilgisayar ve internet kullanımlarında, bölgeler arasında düşük seviyede sayısal bölünmenin bulunduğu tespit edilmiştir. Ayrıca her bölgenin cinsiyetler açısından bölünme düzeylerini gösteren Gini değerleri hesaplanarak, TR9'un en yüksek, TR11'in en düşük sayısal bölünme seviyesine sahip olduğu belirlenmiştir.
\end{abstract}

Anahtar Sözcükler: Bilişim Sistemleri, Eşitsizlik, Sayısal Bölünme, Sayısal Uçurum, Gini Katsayıları

JEL Sınıflandırması: D63, O33

\section{Gini Approach for Determining of Regional Digital Divide in Turkey}

Abstract: Information Technologies that provide many advantages bring some problems depending on the usage differences. Differences that occur between those who can use information technology and who can't has led to inequalities. The issue that has been referred as digital gap or digital divide has deepened and determining the level of inequality caused gain importance by developments in technology. In determining the level of the digital divide computer and internet are often used as indicators, analysis are conducted with statistical methods based on demographic variables. Gini method which is one of the standard tools for the measurement of inequality, is rarely used in digital divide studies. In Turkey, there are no studies to determine the level of digital divide using the Gini coefficients. In this study, the differences between the computer and internet usage levels of people living in Turkey are defined by the Gini approach. The data to determine of these differences were obtained from computer and internet usage research of Level1 Regions in TUIK Household Survey on Information Technology Usage. In this research, it has been determined the digital divide between regions in computer and internet usage is low relatively. Gini coefficients have been calculated among gender for each region and it has been determined that TR9 has the highest and TR11 has the lowest level of the digital divide.

Keywords: Information Systems, Inequalities, Digital Divide, Digital Gap, Gini Coefficients

JEL Classification: D63, O33

${ }^{a}$ Assist. Prof., Mehmet Akif Ersoy University, Faculty of Engineering and Architecture, Burdur, Turkiye, hfidan@mehmetakif.edu.tr 


\section{Giriş}

Teknolojik ilerlemeler sosyal ve ekonomik hayat içerisinde önemli değişikliklere yol açmaktadır. Sosyal dönüşümlere neden olan bu gelişmeler, tarihsel süreçte "Tarım Toplumu" ve "Sanayi Toplumu" olarak isimlendirilen toplumsal yapıların oluşmasına neden olmuştur. Günümüzdeki teknolojik gelişmeler ise bilgi ve iletişim teknolojileri (BIT) tabanlı olduğu için yaşanan süreç "Bilgi Toplumu” olarak nitelenmektedir. Toffler'a göre, bilgi toplumunu şekillendiren araçlardan biri bilgi, diğeri iletişim teknolojileridir (Toffler, 1980). Toplumsal yapıyı doğrudan etkileyen bu araçlar kullanıcılarına birçok imkan sunarken, söz konusu teknolojileri kullanamayan kişiler ise aynı avantajlara kavuşamazlar. Dolayısıyla BiT'i kullanan kişiler ile kullanamayanlar arasında eşitsizlikler ortaya çıkmaktadır.

Biт’e sahiplilikte görülen farklılıklar olarak tanımlanan sayısal bölünme erişim, kullanım ve yetkinlik ile ilgili eşitsizlikleri de içine alan bir kavramdır (Fidan ve Şen). Kişiler, firmalar, bölgeler ve ülkeler arasındaki sosyal eşitsizlikleri arttıran bir problem olarak görülen sayısal bölünme (Attewell, 2001), OECD (2001) tarafindan bilgi açıklığından kaynaklanan fayda farklılıkları olarak tanımlanmaktadır. İlk olarak sabit telefon hattna sahiplilikle duyulmaya başlanan ve birçok gösterge ile ele alınan kavram, günümüzde yoğun olarak bilgisayar kullanımı ve internet erişimi ile değerlendirilmektedir (Brousseau ve Curien, 2007). Yaşam standartları arasında farklılıklara sebep olan sayısal bölünme üzerine yapılan çalışmalar genellikle sayısal bölünme düzeyinin, sebeplerinin ve etkilerinin belirlenmesi üzerinedir. Yabancı literatürde genellikle sayısal bölünme düzeyinin belirlenmesine yoğunlaşıldığı, bu çalışmalarda kişiler ve ülkeler arasındaki sayısal bölünme düzeylerinin belirlenmesinin amaçlandığı görülmektedir (Dewan, Ganley ve Kraemer, 2005; Riggins ve Dewan, 2005). Türkiye'de ise ilk çalışma 1997 yılında Tübitak-Bilten tarafindan gerçekleştirilmiştir. Araştırma sonucunda bilgisayar ve telefon sahiplilik oranları gelir seviyesine göre gruplandırılmış ve kişiler arasında bilgisayar erişimindeki sayısal bölünmenin telefona göre daha yüksek olduğu belirlenmiştir (TubitakBilten, 1999). Sonraki yıllarda yapılan çalışmalarda kavram, dünyadaki çalışmalar ile paralel olarak yaş, gelir, cinsiyet ve eğitim seviyesi gibi değişkenlerle ilişkilendirilerek incelenmiştir (Öztürk, 2005).

Sayısal bölünme düzeyini belirlemek amacıyla kullanılan ölçüm metotları, konuya farklı yaklaşımlar getirmekle beraber aynı zamanda yöntem karmaşası oluşturmaktadır. Farklı göstergelerin ve indekslerin kullanılması sebebiyle yapılan çalışmalar ortak bir zeminde buluşamamaktadır. Araştırmalarda sayısal bölünme düzeyi, genellikle bilgisayar ve internet erişim farklılıklarının, cinsiyet, etnik köken, gelir, eğitim durumu gibi demografik değişkenlerle olan ilişkisi, geleneksel istatistiki yöntemler ile ölçülmeye çalışılmaktadır (NTIA, 2000; NTIA, 2002; Brousseau ve Curien, 2007). Uluslararası kuruluşlar ise farklı BiT göstergelerinin bileşiminden oluşan indeksler kullanmaktadırlar. Sayısal bölünme düzeylerinin ölçülmesinde bileşik ve ayrık olmak üzere iki yaklaşımın kullanıldığını vurgulayan Fidan, her iki yöntemin de sayısal bölünme düzeyini belirlenmesinde yetersizlikleri olduğunu ileri sürmektedir (Fidan, 2016). Corrocher ve Ordanini'ye göre BiT kullanımında sadece durum tespiti gerçekleştiren bu indeksler, sayısal bölünmenin ölçülmesine uzak yaklaşımlardır (Corrocher ve Ordanini, 2002). Diğer taraftan eşitsizliklerin sayısal olarak belirlenmesinde yaygın olarak kullanılan Gini katsayıları, sayısal bölünme düzeyinin ölçülmesinde de kullanılabilir. Araştırmacılar tarafindan eşitsizliklerin belirlenmesinde Gini katsayılarının en iyi araçlardan biri olduğu vurgulansa da (Maclachlan ve Sawada, 1997), sayısal bölünme literatüründe birkaç çalışmada yer verilmiş, Türkiye'de ise söz konusu yöntemin kullanıldığı bir çalışmaya rastlanmamıştır. Bu çalışmada, Türkiye istatistiki bölge birimleri ile belirlenen Düzey1 bölgeleri arasında bilgisayar ve internet erişim farklılıklarının Gini katsayıları ile belirlenmesi amaçlanmaktadır.

\section{Biт 'teki Gelişmeler ve Eşitsizlik}

Son yüzyılda görülen teknolojik gelişmeler kişiler, bölgeler ve ülkeler arasında farklıııkların artmasına neden olmuştur. BiT’te görülen iki önemli gelişme bu farklılıkları olumsuz etkilemiş ve yeni bir eşitsizliğin oluşmasına yol açmıştır. Toplumsal ve ekonomik hayatta devrim niteliğinde değişikliklere yol açan bu gelişmelerden ilki kişisel bilgisayarların (PC) icat edilmesi, ikincisi ise internettir.

Bilgisayar sistemlerinin temeli milattan önceki yıllara dayandırılsa da, günümüzde kullanılan PC'lerin icat edilmesi 1980 yılında gerçekleşmiştir (Gromov, 2012). illk yıllarda oldukça pahalı olan PC'ler, 3000 dolar 
gibi yüksek fiyatları sebebiyle herkes tarafindan alınamıyordu. Ayrıca PC'lerde yapılacak işlemler için gerekli yazııımların da satın alınması ayrı bir maliyet getirmektedir (Gromov, 2012). Diğer taraftan söz konusu yazılımların kullanılması belirli bir deneyim ve eğitim gerektirmektedir. Bu sebeple bilgisayar sahipliğinde ekonomik sebeplerden dolayı yaşanan eşitsizlikler, yazılımların kullanılması noktasında da görülmektedir.

1960 yılında keşfedilen internet yeni nesil bir iletişim aracı olarak hayatımıza 1990'lı yıllarda girmiştir. íki bilgisayar arasındaki iletişimin sağlanması amacıyla oluşturulan sistemin çalışması, telefon hatları üzerinden olmaktadır. Başka bir deyişle ilk yıllarda internetin kullanılabilmesi bilgisayar sahipliği ve telefon hatt sahipliğine bağııdır. Kablosuz ağlar ve akıllı telefonlar gibi günümüz teknolojileri ile bu bağımlılık azalmış olsa dahi, sistemin düşük maliyetle işletilmesi halen telefon hatları üzerinden devam etmektedir. Bu durum, telefon hatt veya bilgisayarı olmayanların interneti kullanamayacağı anlamına gelmektedir. Ayrıca internet tabanlı sistemlerin geliştirilmesi, internet kullananların fayda düzeylerini arttırmaktadır (Gamukama ve Popov, 2011). Bu sebeple internet kullananlar ve kullanmayanların refah düzeyleri arasında farklılıklar oluşmaktadır.

\section{Sayısal Bölünme}

\subsection{Sayısal Bölünme Tanımı}

Toplumdaki gelir dengesizliğinin, sosyal eşitsizliklere sebep olacağı ve bunun ise yoksulluğa neden olacağı genel kabul görmektedir. Benzer şekilde, Biт dağılımındaki eşitsizlikler de toplumda yeni bir yoksulluğu sebep olmaktadır. Cacares'e göre bu yeni yoksulluk, ekonomik yoksulluktan farklı olup, gelir seviyesi yüksek olan kişi ve ülkelerde de yaşanabilir (Cacares, 2007). Sayısal bölünmeyi bir eşitsizlik olarak gören Baker’a göre kavram, dağılımda yaşanan bir dengesizlik halidir (Baker, 2001). Bir başka görüşe göre sayısal bölünme, BiT erişimine sahip olanlar ile olmayanların ayrımı olarak ifade edilmektedir (Riggins ve Dewan, 2005).

Literatürde yer alan tanımlar genellikle Biт'e sahip olanlar ve olmayanlar şeklinde sınıflandırılarak yapılmaktadır. Ancak bazı çalışmalarda kavramın sadece erişimle ilgili olmadığı, Biт’e sahip olunduktan sonra dahi sayısal bölünmenin söz konusu olabileceği vurgulanmaktadır (Hargittai, 2002; Belanger ve Carter, 2006; Sedimo, Bwalya ve Plessis, 2011). Bu yaklaşımı benimseyen çalışmalarda, referans olarak kullanılan tanım OECD tarafindan yapılmıştır (OECD, 2001). Bu tanımda sayısal bölünme kişilere, firmalara ve coğrafi alanlara göre, Bіт erişim ve kullanımlarındaki farklılıklar şeklinde ifade edilmektedir. Söz konusu tanım ile sayısal bölünmenin, fiziksel erişimin yanı sıra, etkin kullanımlarla da ilişkili olduğu vurgulanmaktadır.

\subsection{Sayısal Bölünme Düzeyleri}

Teknolojik, sosyoekonomik, politik ve kültürel yapıdan doğrudan etkilenen bir kavram olan sayısal bölünme, toplumsal farklılıklara göre değişkenlik gösterir. Bu değişkenliğin dinamik bir yapı kazandırdığı sayısal bölünme kavramında farklı düzeylerin olduğu belirtilmektedir (Attewell, 2001; Selwyn, 2004; Nielsen, 2006; VanDijk, 2012). Attewell'e göre sayısal bölünmenin, BiT'e sahip olma süreci ve kullanım süreci olmak üzere iki düzeyi bulunmaktadır. Sahip olma süreci, sayısal bölünmenin başlangıç aşamasında görüldüğü için "birinci seviye sayısal bölünme" veya "yatay bölünme" olarak ifade edilmektedir. BiT'in kullanım sürecinde karşılaşılan sayısal bölünme ise "ikinci seviye sayısal bölünme" veya "dikey bölünme" olarak nitelenmektedir (Attewell, 2001). Fiziksel sahiplilik ile ilgili olan dikey bölünme (VanDijk ve Hacker, 2003), BiT'e sahip olanlar ile olmayanlar arasındaki erişim farklılıklarını ifade eder (Sedimo vd., 2011; Wei ve Hindman, 2011). Fiziksel erişimden daha kapsamlı olan yatay bölünme ise BiT'in etkin kullanımı ile ilgilidir (Selwyn, 2004).

Sayısal bölünmede ekonomik, kullanım ve yetkinlik bölünmesi şeklinde üç düzeyin olduğunu belirten Nielsen, ekonomik bölünme düzeyini, ekonomik sebeplerden dolayı Віт'e sahip olamama durumu olarak açıklamıştr. Kullanım bölünmesi, BiT'e sahip olanların BiT kullanım becerileri arasındaki farklııklar, yetkinlik bölünmesi ise sahip olunan BiT'in tüm imkanlarının kullanılması ile ilgilidir (Nielsen, 2006). Aynı düzeyleri farklı isimlerle niteleyen Kado'ya göre sayısal bölünmede uyum, kalkış ve doygunluk düzeyleri bulunmaktadır

(Kado, 2004). Sosyolojik açıdan sayısal bölünmeyi inceleyen VanDijk, kavramın motivasyon, sahiplilik, yetenek ve kullanım farkı düzeylerine sahip olduğunu vurgulamıştır. Diğer çalışmalarda rastlanmayan motivasyon 
düzeyi ile VanDijk, henüz BiT'e sahip olmayanlar arasında da sayısal bölünmenin olacağını ifade etmektedir (VanDijk, 2012). Bu çerçevede motivasyon düzeyi, BiT edinmeye istekli olanlar ile istekli olmayanlar arasındaki sayısal bölünmeyi işaret etmektedir.

\section{Eşitsizliklerin Ölçülmesi ve Gini Katsayıları}

Sayısal bölünme ile ilgili çalışmalar genellikle kişisel, bölgesel veya küresel bölünme seviyelerinin belirlenmesi amacıyla yapılmaktadır. Birleşmiş Milletler, Dünya Bankası ve OECD gibi organizasyonlar, sayısal bölünmenin küresel boyutlarını ele almakta, çözüm önerileri getirmektedir. Farklı indeksler, parametreler ve analizlerin kullanıldığı araştırmalarda, sayısal bölünmenin küresel bir problem olduğu vurgulanmaktadır. Bu araştrrmalarda ICT Development Index (IDI), Digital Evolution Index (DEI) ve Networked Readiness Index (NRI) gibi indeksler kullanılmaktadır. Bu indekslerde bilgisayar, internet ve mobil telefon sahiplilikleri parametre olarak yer almaktadır (Fidan, 2016).

Sayısal bölünme ile ilgili gerçekleştirilen ilk çalışma "National Telecommunications and Information Administration" (NTIA) tarafindan Amerika Birleşik Devletleri'nde gerçekleştirilmiştir. 1995 yılında yayınlanan ilk raporda, Віт kullanımlarının cinsiyet, yaş, gelir düzeyi gibi bazı demografik değişkenlere göre farklılıkları incelenmiştir (NTIA, 1995). OECD'nin 2001 yılında yayınladığı “Understanding Digital Divide" isimli raporu, ülkeler arasındaki BiT sahipliliği ile ilgili farklııkları ortaya koyan bir çalışmadır. OECD ülkelerinin BiT sahiplilik ve fiyat seviyelerini karşılaştıran çalışma, telefon, bilgisayar ve internet sahiplilik oranlarından yararlanarak, ülkelerin BiT’e hazır olup olmadığını incelemektedir. Sayısal bölünme ile küresel anlamda ilgilenen diğer bir kuruluş olan Birleşmiş Milletler (BM) tarafindan yapılan araştırmalarda, ülkeler arasındaki sayısal bölünmenin arttı̆ı ve bunun sebebinin BiT'teki gelişmeler olduğu vurgulanmaktadır (UNDP, 1999).

Sayısal bölünme kavramı akademik çevreler tarafindan da geniş biçimde incelenmektedir. Literatürdeki çalışmalar genellikle küresel ve bölgesel çerçevede kişiler arasındaki sayısal farklılıkları konu almaktadır. Bu çalışmalarda, BiT kullanımları arasındaki farklılıklar yaş, cinsiyet gibi demografik değiş̧kenlere göre geleneksel istatistiki yöntemler ile incelenmektedir. Çalışmaların 1990'lı yıllarda başladığı ve genellikle kişiler ve ülkeler arasındaki bölünme düzeylerinin incelendiği görülmektedir (Selwyn, 2004). Farklı yaklaşımların kullanıldığı araştırmalarda cinsiyet, yaş, ırk, bölge ve gelir seviyesi gibi değişkenlere göre Biт sahiplilikleri, yüzde değerleri hesaplanarak değerlendirilmektedir.

Kişisel bilgisayar, ana bilgisayar (mainframe) ve internet sahiplilik oranları ile sayısal bölünme düzeyini belirlemeye çalışan Dewan vd. (2005), eski teknolojilerde sayısal bölünmenin daha az olduğunu ve sayısal bölünme düzeyini etkileyen başlıca faktörün gelir seviyesi olduğunu ifade etmiştir. Chakraborty ve Bosman'ın, gelir grupları ve ırklara göre sayısal bölünmeyi inceledikleri çalışmalarında, etnik kökenler arasındaki sayısal bölünmenin, orta gelir grubunda daha fazla olduğunu belirlemişlerdir (Chakraborty ve Bosman, 2002). Başka bir çalışmada internet erişimi ve mobil telefon sahipliğindeki farklılıkların eğitim ve gelir ile ilişkili olduğu tespit edilmiştir (Rice ve Katz, 2003). Kentsel ve kırsal bölgelerdeki sayısal bölünmeyi araştıran Stern, Adams ve Elsasser (2009), Віт kullanımlarının kırsal alanlarda düşük seviyelerde olduğunu belirlemiştir. Teknolojik gelişmelerin kişisel ve bölgesel eşitsizliklere neden olduğunu belirten Sharma ve Gupta, günümüzde internet tabanlı uygulamaların sayısal bölünmeyi arttırdığını vurgulamıştır (Sharma ve Gupta, 2014).

\subsection{Gini Katsayıları}

iktisadi görüşe göre sınırlı olan kaynakların dağılımındaki dengesizlikler, kişiler arasında eşitsizliklere neden olur. Kaynakların insanlar arasında eşit olmayan bir şekilde paylaşılması, toplumda refah seviyelerinin farklı olmasına ve dolayısıyla toplam refahta azalmaya yol açar. Genel anlamda eşitsizlik, dağılımların farklılık göstermesi olarak tanımlanmaktadır (Karoly, 1992). Çeşitli ölçüm araçlarının olmasına karşın, eşitsizliklerin ölçülmesinde kullanılacak en iyi yöntem Gini katsayılarıdır (Maclachlan ve Sawada, 1997). Corrado Gini tarafindan geliştirilen yöntem, gelir dağılımlarında görülen eşitsizliği sayısal bir değer ile belirleme imkanı sağlamaktadır (Ceriani ve Verme, 2012). Gini katsayısının hesaplanmasında ise Lorenz eğrisi referans alınmaktadır. Nüfus içerisindeki gelir dağılımı eşitsizliklerini gösteren Lorenz eğrisi Şekil 1' de görülmektedir. 
Şekil 1. Lorenz Eğrisi

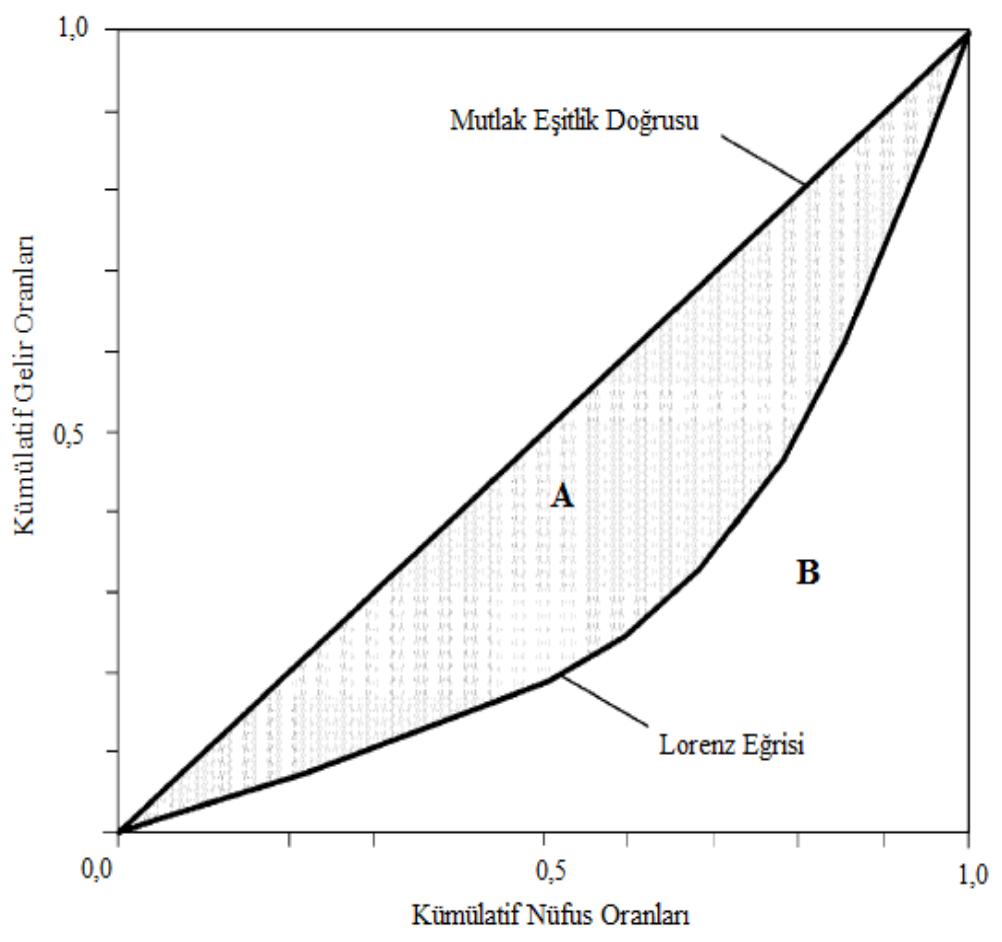

Lorenz eğrisi eşitsizliklerin grafiksel olarak değerlendirilmesinde güçlü bir araçttr. Ancak farklı eşitsizliklerin karşılaştırılması ve yorumlanması noktasında yetersiz kalmaktadır. Bu yetersizlik eğriyle oluşan alanların oranlanması ile aşılabilir. Temel Gini yaklaşımı olan bu oransal işlem (1) nolu denklemde görülmektedir.

$$
\begin{aligned}
G & =\frac{A}{A+B} \\
G & =\frac{1}{n}\left(n+1-2 \frac{\sum_{i=1}^{n}(n+1-i) y_{i}}{\sum_{i=1}^{n} y_{i}}\right) \\
G & =\sum_{i=1}^{n}\left|X_{i} Y_{i+1}-X_{i+1} Y_{i}\right|
\end{aligned}
$$

Gini katsayısı, Lorenz eğrisindeki alanlar kullanılmadan (2) nolu denklem ile hesaplanabilir. Denklemde $n$ adet grubun her biri $i$ ile gösterilmekte, $Y_{i}$ kümülatif gelir yüzdesini ifade etmektedir (Shankar ve Shah, 2003). Gini değerinin nüfus bilgisine yer verilmeden hesaplandığı söz konusu denklem, nüfusun eşit dağılımda olduğu varsayımı altında kullanılabilir. Ancak farklı nüfus büyüklüklerine sahip bölgelerin analizinde, hesaplamaların nüfusa göre ağırlıklandırıması daha sağlıklı sonuçlar ortaya çıkaracaktır. Bu durumda Gini katsayılarının hesaplanmasında (3) nolu denklem kullanılmalıdır. Denklemde $n$ bölge sayısını, $X_{i}$ i'nci bölge kümülatif nüfus oranını, $Y_{i}$ i'nci bölge kümülatif gelir oranını göstermektedir. Söz konusu denklem kullanılarak yapılacak hesaplama öncesi, gelir gruplarının küçükten büyüğe doğru sıralanmasının gerektiği vurgulanmaktadır (Maclachlan ve Sawada, 1997).

Yukarda verilen denklemler ile hesaplanacak Gini değeri 0 ile 1 aralığında oluşur. Eşitsizliğin azalması halinde Gini değeri sıfir, artması halinde bire yaklaşır. Başka bir deyişle Gini değerinin sıfir olarak hesaplanması tam eşitlilik, 1 olarak hesaplanması ise tam eşitsizlik anlamına gelmektedir. 


\subsection{Sayısal Bölünmenin Gini Katsayılarıyla Belirlenmesine Yönelik Çalışmalar}

Sayısal bölünme ile ilgili literatür incelendiğinde çalışmaların sayısal bölünme seviyesinin belirlenmesi, sebepleri ve etkileri üzerine olduğu söylenebilir. Sayısal bölünmenin ölçülmesi ile ilgili çalışmalarda genel olarak istatistiksel yaklaşımlar kullanılmaktadır. Bu çalışmalarda kullanılan yüzde oranlar ikili karşılaştırmalarda anlamlı sonuçlar verebilir, ancak daha fazla sayıdaki grubun eşitsizlik seviyelerinin karşılaştırılmasında yetersiz kalmaktadır. Diğer taraftan eşitsizliklerin hesaplanmasında kullanılan Lorenz eğrisi ve Gini katsayıları gibi yöntemlere literatürde nadiren rastlanmaktadır.

Ülkeler, firmalar ve kişiler arasındaki sayısal bölünmeyi Gini yaklaşımı kullanarak ölçen Riccardini ve Fazio, en yüksek sayısal bölünmenin ülkeler arasında sunucu sistemlerinde, kişiler arasında ise internet tabanlı uygulamalarda yaşandığını tespit etmişlerdir. Ayrıca çalışmada coğrafi lokasyon ve firma büyüklüğünün, İtalya'da faaliyet gösteren firmalar arasındaki sayısal bölünmeyi ortaya çıkaran faktörler olduğu belirlenmiştir (Riccardini ve Fazio, 2002).

Gini metodu kullanılarak, ABD'deki nüfus yoğunlukları birbirinden farklı eyaletler arası sayısal bölünme düzeylerini inceleyen Chakraborty ve Bosman, bilgisayar sahiplilik ve internet erişim oranlarını gelir gruplarına göre analiz etmiştir. Nüfusun 14 farklı gelir grubuna ayrılarak gerçekleştirildiği analizin sonuçları gelir seviyesi çerçevesinde ortaya konulmuştur (Chakraborty ve Bosman, 2005).

Amerika ve Kanada'nın internet erişim oranlarını kullanarak eğitim ve gelir gruplarına göre sayısal bölünme düzeylerini Gini ile inceleyen Howard, Busch ve Sheets, eğitimin her iki ülkedeki sayısal bölünme üzerinde ciddi etkilerinin olduğunu belirlemişlerdir. Ayrıca Kanada'nın hem gelir hem de eğitim grupları açısından Amerika'ya nazaran daha düşük Gini katsayılarına sahip olduğu saptanmıştır (Howard, Busch ve Sheets, 2010).

Jin ve Cheong'un demografik değişkenlere göre sayısal bölünmeyi inceledikleri çalışmada, internet erişimi ve internet kullanımı Gini katsayıları hesaplanmıştı. Bu katsayılar arasında bir ilişkinin bulunmadığı ifade edilen araştırmada, kullanım ve erişimlerdeki eşitsizliklerin zamana göre değiştiği tespit edilmiştir (Jin ve Cheong, 2008).

Fidan ve Şen, Türkiye'de kent ve kırsal alanlardaki sayısal bölünme düzeylerini Gini katsayılarıyla hesaplamışlardır. Çalışmada en yüksek sayısal bölünmenin internet bankacılığı, en düşük sayısal bölünmenin ise mobil telefon sahipliğinde olduğu belirlenmiştir. Ayrıca kırsal alanlarda cinsiyetler arası sayısal bölünme düzeyinin tam eşitsizliğe oldukça yakın olduğu tespit edilmiştir (Fidan ve Şen, 2015).

Gini yaklaşımının sayısal bölünmenin ölçülmesinde bir standart oluşturabileceğini öne süren Fidan, Türkiye ve Litvanya sektörler arası sayısal bölünme düzeylerini Gini katsayıları ile belirlemiştir. Çalışmada, BiT sahiplilik yüzdelerinin Litvanya'da yüksek olmasına karşın, sektörler arası sayısal bölünmenin Türkiye'ye nazaran daha yüksek olduğu tespit edilmiştir. Bu bağlamda çalışmada, sayısal bölünme düzeyini belirlemek için kullanılan IDI ve NRI gibi indekslerin sayısal bölünme ile ilgili gerçek durumu yansıtmadığı kanıtlanmıştır (Fidan, 2016).

\section{Yöntem}

\subsection{Araştırmanın Amacı}

Türkiye'de Düzey1 bölgelerinde internet ve bilgisayar kullanım oranlarının temel alındığı çalışmada, cinsiyetler arasındaki sayısal bölünme düzeylerinin Gini yaklaşımıyla ölçülmesi amaçlanmaktadır. Bu sayede 12 tane olan Düzey1 grupları arasındaki bölünme seviyesi, sayısal olarak belirlenebilecektir.

\subsection{Araştırma Veri Seti ve Kapsamı}

Araştırma veri seti, TÜik'in yayınladığı "Hanehalkı Bilişim Teknolojileri Kullanım Anketi" ile "Nüfus ve Demografi İstatistikleri" kullanılarak oluşturulmuştur. İstatistiki Bölge Birimleri Sınıflaması Düzey1'e göre bireylerin bilgisayar ve internet kullanım oranlarının yayınlanması 2011 yılı itibariyle başlamıştır. Bu sebeple veri seti, 2011-2014 arası TÜiK anketine katılan kişileri kapsamaktadır. İstatistiki Bölge Birimleri Sınıflaması 
Düzey1 bölgelerinde yer alan illerin isimleri Tablo 1, bölgelerin toplam nüfus bilgileri ile bölgelerde yaşayan erkek ve kadınların sayısı Ek 1'de verilmiştir. Ayrıca bölgelerdeki bilgisayar ve internet kullanım oranları sırasıyla Ek 2 ve Ek 3'te verilmiştir. Bu oranlar temel alınarak hesaplanan bilgisayar ve internet kullanan kişi sayıları ise Ek 4 ve Ek 5'te sunulmuştur.

Tablo 1. Düzey1 Bölge illeri

\begin{tabular}{|c|l|}
\hline Bölgeler & \multicolumn{1}{|c|}{ iller } \\
\hline TR1 & İstanbul \\
\hline TR2 & Tekirdağ, Edirne, Kırklareli, Balıkesir, Çanakkale \\
\hline TR3 & İzmir, Aydın, Denizli, Muğla, Manisa, Afyon, Kütahya, Uşak \\
\hline TR4 & Bursa, Eskişehir, Bilecik, Kocaeli, Sakarya, Düzce, Bolu, Yalova \\
\hline TR5 & Ankara, Konya, Karaman \\
\hline TR6 & Antalya, Isparta, Burdur, Adana, Mersin, Hatay, Kahramanmaraş, Osmaniye \\
\hline TR7 & Kırıkkale, Aksaray, Niğde, Nevşehir, Kırşehir, Kayseri, Sivas, Yozgat \\
\hline TR8 & Zonguldak, Karabük, Bartın, Kastamonu, Çankırı, Sinop, Samsun, Tokat, Çorum, Amasya \\
\hline TR9 & Trabzon, Ordu, Giresun, Rize, Artvin, Gümüşhane \\
\hline TR10 & Erzurum, Erzincan, Bayburt, Ağrı, Kars, Iğdır, Ardahan \\
\hline TR11 & Malatya, Elazı̆̆, Bingöl, Tunceli, Van, Muş, Bitlis, Hakkari \\
\hline TR12 & Gaziantep, Adıyaman, Kilis, Şanlıurfa, Diyarbakır, Mardin, Batman, Şırnak, Siirt \\
\hline
\end{tabular}

\section{Araştırma Bulguları}

Türkiye genelinde bölgeler arası bilgisayar kullanım farklılıklarını ifade eden Gini değerinin 2011 yılı için hesaplanması Tablo 2'de verilmiştir. Söz konusu tablo oluşturulurken ilk olarak bölgelerin bilgisayar kullanan kişi sayıları ve nüfusları tespit edilmiştir. Her bir bölgenin tüm bölgeler içerisindeki bilgisayar kullanım oranı $\left(y_{i}\right)$ ve nüfus oranı $\left(x_{i}\right)$ hesaplanmıştır. Kümülatif değerlerin belirlenmesinden önce, diğer çalışmalarda gelir seviyesine göre küçükten büyüğe doğru yapılan sıralama, bu çalışmada bilgisayar kullanan kişi sayılarına göre yapılmış, sonrasında kümülatif değerler hesaplanmıştır.

Tablo 2. Gini Katsayılarının Hesaplanması

\begin{tabular}{cccccc}
\hline & $\begin{array}{c}\text { Bilgisayar kullanım } \\
\text { oranı }\left(y_{i}\right)\end{array}$ & $\begin{array}{c}\text { Nüfus oranı } \\
\left(x_{i}\right)\end{array}$ & $\begin{array}{c}\text { Kümülatif } \\
\text { bilgisayar kullanım } \\
\text { oranı }\left(Y_{i}\right)\end{array}$ & $\begin{array}{c}\text { Kümülatif Nüfus oranı } \\
\left(X_{i}\right)\end{array}$ & $\left|X_{i} Y_{i+1}-X_{i+1} Y_{i}\right|$ \\
\hline TR10 & 0,023851 & 0,029848 & 0,023851 & 0,029848 & 0,000177 \\
TR9 & 0,032804 & 0,033631 & 0,056655 & 0,063479 & 0,000555 \\
TR11 & 0,035563 & 0,049647 & 0,092218 & 0,113126 & 0,00081 \\
TR2 & 0,042185 & 0,04296 & 0,134402 & 0,156086 & 0,000918 \\
TR7 & 0,050174 & 0,051439 & 0,184577 & 0,207525 & 0,000528 \\
TR8 & 0,050746 & 0,059915 & 0,235323 & 0,26744 & 0,007439 \\
TR12 & 0,064224 & 0,1046 & 0,299546 & 0,37204 & 0,012301 \\
TR4 & 0,107977 & 0,093045 & 0,407523 & 0,465084 & 0,012285 \\
TR5 & 0,110415 & 0,095865 & 0,517939 & 0,56095 & 0,009427 \\
TR6 & 0,120911 & 0,127078 & 0,638849 & 0,688027 & 0,044743 \\
TR3 & 0,134081 & 0,129646 & 0,77293 & 0,817673 & 0 \\
TR1 & 0,22707 & 0,182327 & 1 & 1 & Toplam=0,09119 \\
\hline
\end{tabular}

On iki grup ile oluşturulan Tablo 2'nin sıralanması ile bilgisayar kullanımı açısından en düşük bölge olan ve nüfusun \%2,9'unu ifade eden TR10'un, bilgisayar kullanımları içerisindeki payının \%2,3 olduğu görülmektedir. Bilgisayar kullanımından \%22,7 ile en fazla payı alan bölge ise nüfusun \%18,2'sini oluşturan TR1'dir. Bu değerler TR1 ile TR10 arasında bilgisayar kullanımı açısından büyük bir farklılık olduğu izlenimini vermektedir. Önceki bölümde yer alan (3) nolu denklem kullanılarak gerçekleştirilen hesaplama sonrası Gini değerinin 0,09119 olduğu belirlenmiştir. Yüzdeler dikkate alındığında, bölgeler arasında bilgisayar 
kullanımları açısından büyük farklılıkların olduğu düşünülse de hesaplanan Gini değeri, bölgeler arasında eşit dağılımın olduğunu göstermektedir.

Tablo 2' de verilen yönteme göre 2011-2014 yıllarında toplam nüfus (T), erkek nüfus (E) ve kadın nüfus (K) arasındaki bilgisayar kullanımları Gini değerleri hesaplanarak Tablo 3'te sunulmuştur. Söz konusu tabloda, bölgeler arası bilgisayar kullanım farklılıklarının yıllar itibariyle giderek azaldığı görülmektedir. 2014 yılı itibariyle 0,055 olan erkekler arasındaki sayısal bölünme seviyesi, kadınlardan daha düşüktür.

Tablo 3. Bilgisayar Kullanımları Gini Değerleri

\begin{tabular}{ccccc}
\hline Gruplar & $\mathbf{2 0 1 1}$ & $\mathbf{2 0 1 2}$ & $\mathbf{2 0 1 3}$ & $\mathbf{2 0 1 4}$ \\
\hline $\mathrm{T}$ & 0,091 & 0,110 & 0,089 & 0,075 \\
$\mathrm{E}$ & 0,068 & 0,077 & 0,061 & 0,055 \\
$\mathrm{~K}$ & 0,122 & 0,158 & 0,137 & 0,101 \\
\hline
\end{tabular}

$\mathrm{T}$ :Toplam nüfus, E:Erkek nüfus, K:Kadın nüfus

2011-2014 yılları arası internet kullanımı Gini değerleri Tablo 4'te verilmiştir. Bilgisayar kullanımlarının toplam, erkek ve kadın nüfus içerisindeki Gini katsayılarına yakın değerler, internet kullanımları içinde söz konusudur. Ancak internet kullanımı sayısal bölünme seviyeleri, bilgisayar kullanımlarına göre yüksektir. Söz konusu tablodaki değerlere göre bölgeler arasında ciddi bir sayısal bölünmenin bulunmadığı görülmektedir. Ayrıca bilgisayar kullanımlarında hesaplanan değerlere benzer olarak, en yüksek Gini katsayı değerleri yine kadınlar arasındadır. Genel olarak ifade edilecek olursa, Tablo 3 ve Tablo 4, hem bilgisayar hem de internet kullanımlarında, Düzey1 bölgeleri arasında yüksek bir sayısal bölünmenin yaşanmadığını göstermektedir.

Tablo 4. Internet Kullanımları Gini Değerleri

\begin{tabular}{ccccc}
\hline Gruplar & $\mathbf{2 0 1 1}$ & $\mathbf{2 0 1 2}$ & $\mathbf{2 0 1 3}$ & $\mathbf{2 0 1 4}$ \\
\hline T & 0,097 & 0,114 & 0,097 & 0,077 \\
E & 0,071 & 0,076 & 0,064 & 0,056 \\
K & 0,135 & 0,169 & 0,143 & 0,106 \\
\hline
\end{tabular}

T: Toplam nüfus, E: Erkek nüfus, $\mathrm{K}$ : Kadın nüfus

Bölgelerde erkek ve kadın nüfus arasındaki sayısal bölünme düzeyinin belirlenmesi, bilgisayar ve internet kullanımları ile ilgili bölgesel dinamiklerin ortaya çıkarılmasını ve bölgeler arası karşılaştırmaların yapılabilmesini sağlayacaktır. Bu bağlamda her bir bölge için hesaplanan, erkek ve kadınlar arasındaki bilgisayar ve internet kullanım farklılıklarını gösteren Gini değerleri sırasıyla Tablo 5 ve Tablo 6'da sunulmuştur.

Tablo 5. Cinsiyetler Arası Bilgisayar Kullanımı Gini Değerleri

\begin{tabular}{ccccc}
\hline & $\mathbf{2 0 1 1}$ & $\mathbf{2 0 1 2}$ & $\mathbf{2 0 1 3}$ & $\mathbf{2 0 1 4}$ \\
\hline TR10 & 0,186 & 0,171 & 0,161 & 0,152 \\
TR9 & 0,217 & 0,151 & 0,236 & 0,227 \\
TR11 & 0,052 & 0,191 & 0,089 & 0,053 \\
TR2 & 0,098 & 0,066 & 0,177 & 0,074 \\
TR7 & 0,101 & 0,100 & 0,084 & 0,075 \\
TR8 & 0,288 & 0,277 & 0,070 & 0,132 \\
TR12 & 0,051 & 0,071 & 0,180 & 0,120 \\
TR4 & 0,080 & 0,167 & 0,089 & 0,068 \\
TR5 & 0,084 & 0,088 & 0,166 & 0,080 \\
TR6 & 0,105 & 0,022 & 0,025 & 0,092 \\
TR3 & 0,084 & 0,088 & 0,090 & 0,085 \\
TR1 & 0,083 & 0,079 & 0,065 & 0,054 \\
\hline
\end{tabular}


H. Fidan

Tablo 6. Cinsiyetler Arası İnternet Kullanımı Gini Değerleri

\begin{tabular}{ccccc}
\hline & $\mathbf{2 0 1 1}$ & $\mathbf{2 0 1 2}$ & $\mathbf{2 0 1 3}$ & $\mathbf{2 0 1 4}$ \\
\hline TR10 & 0,206 & 0,197 & 0,180 & 0,143 \\
TR9 & 0,241 & 0,176 & 0,242 & 0,233 \\
TR11 & 0,064 & 0,204 & 0,085 & 0,052 \\
TR2 & 0,156 & 0,062 & 0,178 & 0,073 \\
TR7 & 0,058 & 0,109 & 0,118 & 0,085 \\
TR8 & 0,297 & 0,303 & 0,036 & 0,134 \\
TR12 & 0,061 & 0,082 & 0,195 & 0,138 \\
TR4 & 0,085 & 0,172 & 0,090 & 0,073 \\
TR5 & 0,090 & 0,086 & 0,175 & 0,082 \\
TR6 & 0,109 & 0,029 & 0,025 & 0,096 \\
TR3 & 0,084 & 0,088 & 0,089 & 0,087 \\
TR1 & 0,083 & 0,083 & 0,068 & 0,059 \\
\hline
\end{tabular}

Cinsiyetler arası bilgisayar ve internet kullanım farklııklarını ifade eden Gini katsayılarının verildiği Tablo 5 ve Tablo 6 'da, değerlerin yıllar itibariyle giderek azaldığı dikkat çekmektedir. Tüm bölgelerdeki bilgisayar kullanım farklııkları, internete göre daha düşük seviyededir. Ayrıca bilgisayar kullanım farklıı̆ının yüksek olduğu bölgelerde, internet kullanım farklılıklarının da yüksek olduğu görülmektedir. Bilgisayar kullanımı sayısal bölünme seviyesinin 2014 yılı itibariyle en yüksek olduğu bölgeler sırasıyla TR9, TR10 ve TR8 iken, bu sıralama internet için TR9, TR10 ve TR12 şeklindedir. Sayısal bölünmenin en az seviyede olduğu bölgeler ise bilgisayar kullanımında sırasıyla TR11, TR1 ve TR4 iken internet kullanımında TR11, TR1 ve TR2 olarak belirlenmiştir. 2014 yılı itibariyle hem bilgisayar hem de internet kullanımlarında cinsiyetler arası sayısal bölünme seviyesinin, TR9 ve TR10 bölgelerinde yüksek olduğu görülmektedir. TR11 ise cinsiyetler arası sayısal bölünme seviyesinin en az olduğu bölgedir.

\section{Sonuç}

Sayısal bölünme, BiT’teki gelişmelerle birlikte giderek daha fazla önem kazanan bir kavram haline gelmektedir. Kavramsal çalışmaların büyük kısmı sayısal bölünmenin ölçülmesine yöneliktir. Genellikle temel istatistiksel yöntemlerin kullanıldığı çalışmalara, söz konusu seviyenin belirlenmesinde Gini katsayılarının kullanımı ile yeni bir yaklaşım getirilmiştir. Eşitsizliklerin ölçülmesinde yoğun olarak kullanılan Gini yaklaşımı, sayısal bölünme literatüründe nadiren yer almaktadır. Gini kullanan birkaç çalışmada ise Bí kullanımlarında görülen farklılıklar gelir düzeyleri temel alınarak incelenmektedir. Bu çalışmada ise gelire göre gruplandırma yerine, nüfusun bölgesel olarak gruplandırılması yapılarak Gini katsayıları hesaplanmıştır. Bu yöntem, Türkiye'de istatistiki bölge birimleri Düzey1 bölgelerinin bilgisayar ve internet kullanımlarına uygulanarak, sayısal bölünme seviyeleri belirlenmiştir. Böylece sayısal bölünmenin Gini yaklaşımı ile gelir ilişkisi kurulmadan da hesaplanabileceği ortaya konulmuştur.

Düzey1 bölgeleri bilgisayar ve internet kullanımlarının yüzdelik dilimleri, bölgeler arasında büyük farklılıkların olduğu izlenimini vermektedir. Ancak Gini değerlerine göre bölgeler arasında hem bilgisayar hem de internet kullanımlarında sayısal bölünmenin bulunmadığı belirlenmiştir. Hesaplanan Gini değerlerine göre eşitsizliklerin en fazla kadınlar arasında ve internet kullanımlarında olduğu tespit edilmiştir. Ayrıca her grup ve bölgenin Gini değerleri, bilgisayar ve internet kullanımlarında giderek tam eşitliğe yaklaşıldığını ortaya koymaktadır.

Cinsiyetler arası bilgisayar ve internet kullanımlarındaki farklılıklar TR9 haricinde tüm Düzey1 bölgelerinde azalmaktadır. Kuzey Doğu Karadeniz bölgesindeki illeri kapsayan TR9'da görülen cinsiyetler arası sayısal bölünme seviyesi yıllar itibariyle artş eğilimindedir. Ayrıca TR9, bilgisayar ve internet kullanım farklııklarının en yüksek olduğu bölge konumundadır. Söz konusu bölgeden sonraki en yüksek sayısal bölünmeye sahip bölge ise Erzurum, Erzincan, Bayburt, Ağrı, Kars, Iğdır ve Ardahan illerini kapsayanTR10'dur. Diğer taraftan, cinsiyetler arası sayısal bölünmenin en düşük olduğu bölge ise TR11'dir. Malatya, Elazığ, Bingöl, Tunceli, Van, Muş, Bitlis ve Hakkari illerini kapsayan bu bölgenin 2014 yılı Gini değerleri, bilgisayar kullanımında 0,053 ve internet kullanımında 0,052 olarak hesaplanmıştır. İstanbul'u temsil eden TR1 ise 
sayısal bölünmenin en düşük olduğu ikinci bölgedir. TR1'in aynı yıl için Gini değerleri ise bilgisayar kullanımında 0,054 ve internet kullanımında 0,059 olarak hesaplanmıştır.

\section{Kaynaklar}

Attewell, P. (2001). Comment: The first and second digital divides. Sociology of Education, 74(3), 252-259.

Baker, P. M. A. (2001). Policy bridges for the digital divide: Assessing the landscape and gauging the dimensions. First Monday. http://www.firstmonday.org/ojs/index.php/fm/article/view/860/769 (Erişim Tarihi, 20 Mayıs 2015).

Belanger, F., \& Carter, L. (2006). The effects of the digital divide on E-government: An empirical evaluation. Proceedings of the 39th Hawaii International Conference on System Sciences.

Brousseau, E., \& Curien, N. (2007). Internet and digital economics. New York: Cambridge University Press.

Cacares, R. B., "Digital Poverty: Concept and Measurement, With an Application to Peru", Working paper \#337, Kellogg Institute, University of Notre Dame (2007). http://kellogg.nd.edu/publications/workingpapers/WPS/337.pdf, (10.11.2016).

Ceriani, L., \& Verme, P. (2012). The origins of the Gini index: extracts from Variabilitàe Mutabilità (1912) by Corrado Gini. J Econ Inequal, 10, 421-443.

Chakraborty, J., \& Bosman, M. M. (2002). Race, income, and home PC ownership: A regional analysis of the digital divide. Race and Society, 5(2), 163-177.

Chakraborty, J., \& Bosman, M. M. (2005). Measuring the digital divide in the United States: Race, income and personel computer ownership, The Professional Geographer, 57(3), 395-410.

Chowdary, T. H. (2002). Diminishing the digital divide in India. Info, 4(6), 4-8.

Corrocher, N., \& Ordanini, A. (2002). Measuring the digital divide: a framework for the analysis of cross-country differences. Journal of Information Technology, 17, 9-19. http://dx.doi.org/10.1080/02683960210132061

Dewan, S., Ganley, D., \& Kraemer, K. L. (2005). Across the digital divide: A cross-country multi-technology analysis of the determinants of IT penetration. Journal of the Association for Information Systems, 6(12), 409-432.

Dimaggio, P., \& Hargittai, E. (2001). From the digital divide to digital inequality: Studying Internet use as penetration increases. Princeton University Center for Arts and Cultural Policy Studies Working Paper Series, number 15.

Drucker, P. F. (2000). Toward the New Economics, Boston: Harvard Business School Publishing Corporation.

Fidan, H. (2016). Measurement of the Intersectoral Digital Divide with the Gini Coefficients: Case Study Turkey and Lithuania. Engineering Economics, 27(4), 439-451.

Fidan, H. Ve Şen, H. (2015). Sayısal Bölünmenin Ölçülmesinde Gini Yaklaşımı: Türkiy"de Kentsel, Kırsal ve Cinsiyet Açısından Sayısal Bölünme Düzeyleri. Uluslararası Sosyal Araştırmalar Dergisi, 8(39), 1108-1118.

Gamukama, E. A., \& Popov, O. B. (2011). A Social Welfare Approach in Increasing the Benefits from the Internet in Developing Countries. ACEEE Int. J. on Network Security , 2(4), 29-33.

Goodman, L. A., \& Kruskal, W. H. (1959). Measures of association for cross classifications II: Further discussion and references. Journal of the American Statistical Association, 54(285), 123-163.

Hargittai, E. (2002). Second level digital divide: Differences in people's online skills. First Monday, http://journals.uic.edu/ojs/index.php/fm/article/view/942/864 (Erişim Tarihi, 24 Şubat 2015).

Howard, P. N., Busch, L., \& Sheets, P. (2010). Comparing digital divides: Internet access and social inequality in Canada and the United States. Canadian Journal of Communication, 35, 109-128.

Jin, J., \& Cheong, A. W. H. (2008). Measuring digital divide: The exploration in Macao", Observatorio (OBS) Journal, 2(3), $259-272$.

Kado (2004). How to measure the digital divide?. https://www.itu.int/osg/spu/ni/digitalbridges/presentations/02-ChoBackground.pdf (Erişim Tarihi, 21 Kasım 2014).

Kakwani, N. C. (1977). Applications of Lorenz curves in economic analysis. Econometrica, 45(3), 719-728.

Karoly, L. A. (1992). Changes in the distribution of individual earnings in the United States: 1967-1986. The Review of Economics and Statistics, 74(1), 107-115.

Kenny, C. (2003). The internet and economic growth in less-developed countries: A case of managing expectations. Oxford Development Studies, 31(1), 99-113. 
Kim, D. (2008). Widening universal service in Korea to include broadband and mobile communications. Info, 10(5/6), 70-82.

Maclachlan, I., \& Sawada, R. (1997). Measures of income inequality and social polarization in Canadian metropolitan areas. The Canadian Geographer (Le Ceographe Canadien), 41(4), 377-397.

Nielsen, J. (2006). Digital divide: The 3 stages. http://www.nngroup.com/articles/digital-divide-the-three-stages/ (Erişim Tarihi, 21 Kasım 2014).

NTIA (1995). Falling Through The Net: A Survey of the Have Nots in rural and urban America. https://www.ntia.doc.gov/ntiahome/fallingthru.html (Erişim Tarihi, 20 Ocak 2015).

NTIA (1999), Falling through the net: Defining the digital divide. https://www.ntia.doc.gov/legacy/ntiahome/fttn99/contents.html (Erişim Tarihi, 20 Ocak 2015).

NTIA (2000), Falling through the net: Toward digital inclusion. https://www.ntia.doc.gov/legacy/ntiahome/fttn00/contents00.html (Erişim Tarihi, 20 Ocak 2015).

NTIA (2002), A nation online: Internet use in America. https://www.ntia.doc.gov/report/2002/nation-online-internetuse-america (Erişim Tarihi, 20 Ocak 2015).

OECD, Understanding the digital divide. https://www.oecd.org/sti/1888451.pdf (Erişim Tarihi, 12 Aralık 2014).

Öztürk, L. (2005). Türkiye'de Dijital Eşitsizlik: TÜBiTAK-BiLTEN Anketleri Üzerine Bir Değerlendirme. Erciyes Üniversitesi iktisadi ve Idari Bilimler Fakültesi Dergisi, Sayı: 24, 111-131.

Riccardini, F., \& Fazio, M. (2002). Measuring the digital divide. IAOS Conference, London. http://www.websm.org/db/12/170/rec/ (Erişim Tarihi, 18 Kasım 2014).

Rice, R. E., \& Katz, J. E. (2003). Comparing internet and mobile phone usage: Digital divides of usage, adoption, and dropouts. Telecommunications Policy, 27(8-9), 597-623.

Riggins, F. J., \& Dewan, S. (2005). The digital divide: Current and future research directions. Journal of the Association for Information Systems, 6(12), Article 13.

Sedimo, N. C., Bwalya, K. J., \& Plessis, T. D. (2011). Conquering the digital divide: Botswana and South Conquering the digital divide: Botswana and South Korea digital divide status and interventions. SA Journal of Information Management, 13(1), Art. \#471.

Selwyn, N. (2004). Reconsidering political and popular understandings of the digital divide. New media \& society, 6(3), 341-362.

Shankar, R., \& Shah, A. (2003). Bridging the economic divide within countries: A scorecard on the performance of regional policies in reducing regional income disparities. World Development, 31(8), 1421-1441.

Sharma, S. K., \& Gupta, J. N. D. (2014). Socio-Economic influences of e-commerce adoption. Journal of Global Information Technology Management, 6(3), 3-21.

Stern, M. J., Adams, A. E., \& Elsasser, S. (2009). Digital inequality and place: The effects of technological diffusion on internet proficiency and usage across rural, suburban, and urban counties. Sociological Inquiry, 79(4), 391-417.

Toffler, A. (1980). The Third Wave, New York: Bantam Books.

Tubitak-Bilten (1999). Türkiye Ulusal Enformasyon Altyapısı Ana Planı Sonuç Raporu, www.bilgitoplumu.gov.tr/documents/1/yayinlar/991000_tuenarapor.pdf (Erişim Tarihi: 5 Kasım 2016).

UNDP (1999). Human Development Report. New York: Oxford University Press.

VanDijk, J., \& Hacker, K. (2003). The digital divide as a complex and dynamic phenomenon. The Information Society, 19, 315-326.

VanDijk, J. (2012). The evolution of the digital divide: The digital divide turns to inequality of skills and usage. Digital Enlightenment Yearbook, 57-75.

Wei, L., \& Hindman, D. B. (2011). Does the digital divide matter more? Comparing the effects of new media and old media use on the education-based knowledge gap. Mass Communication and Society, 14(2), 216-235.

TÜiK (2015). Hanehalkı Bilişim Teknolojileri Kullanım Araştırması. http://www.tuik.gov.tr (Erişim Tarihi, 15 Nisan 2015). 

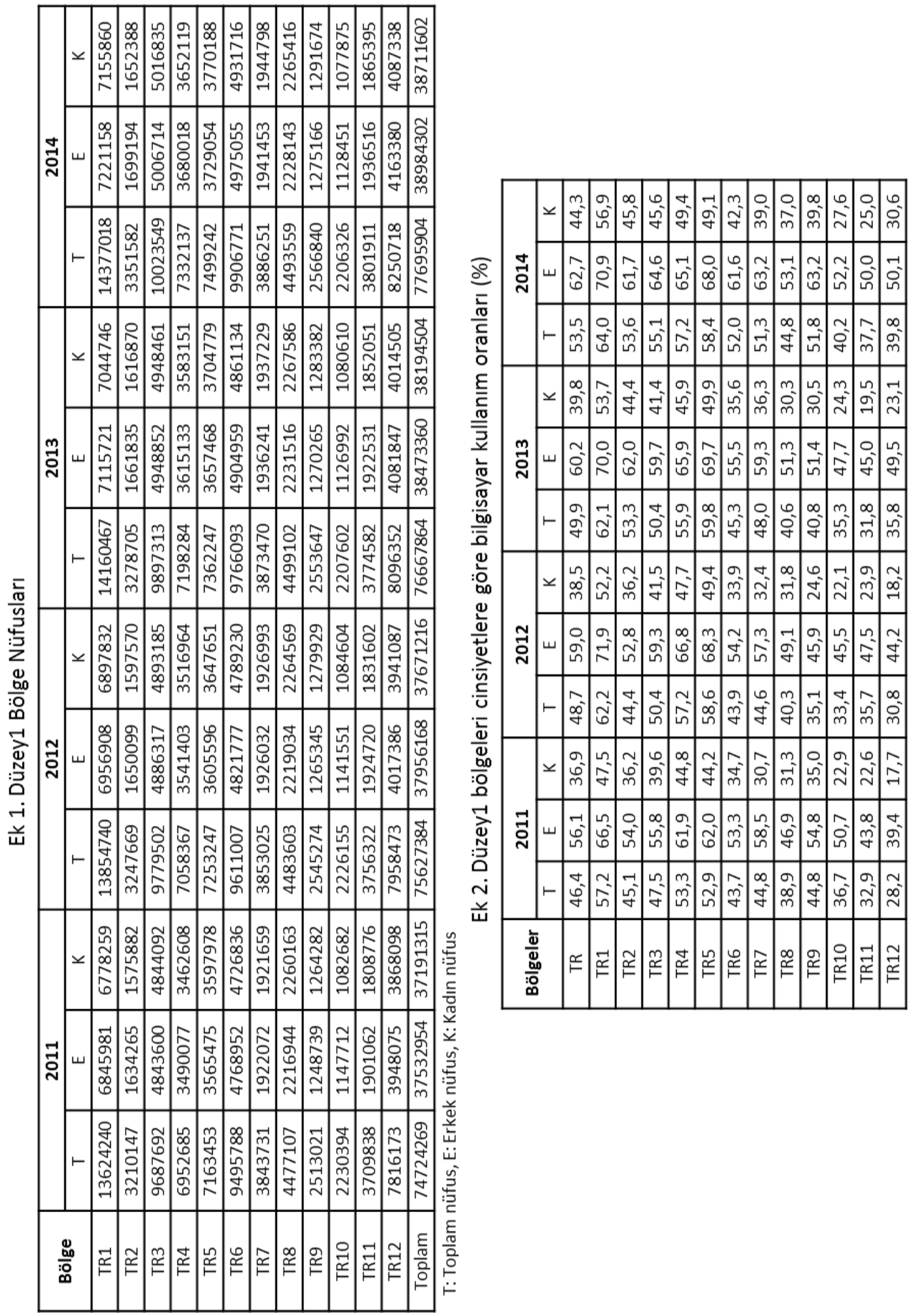

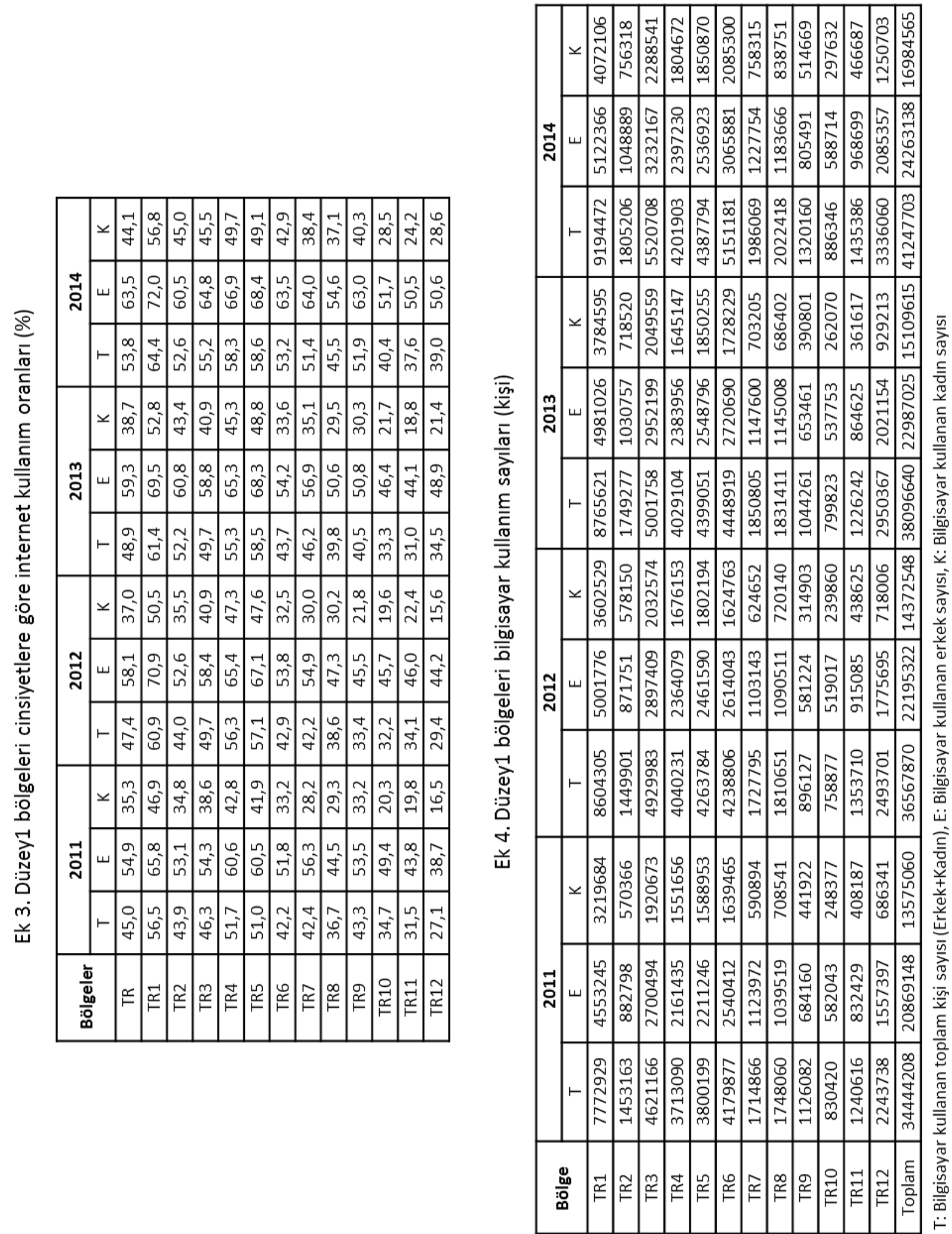


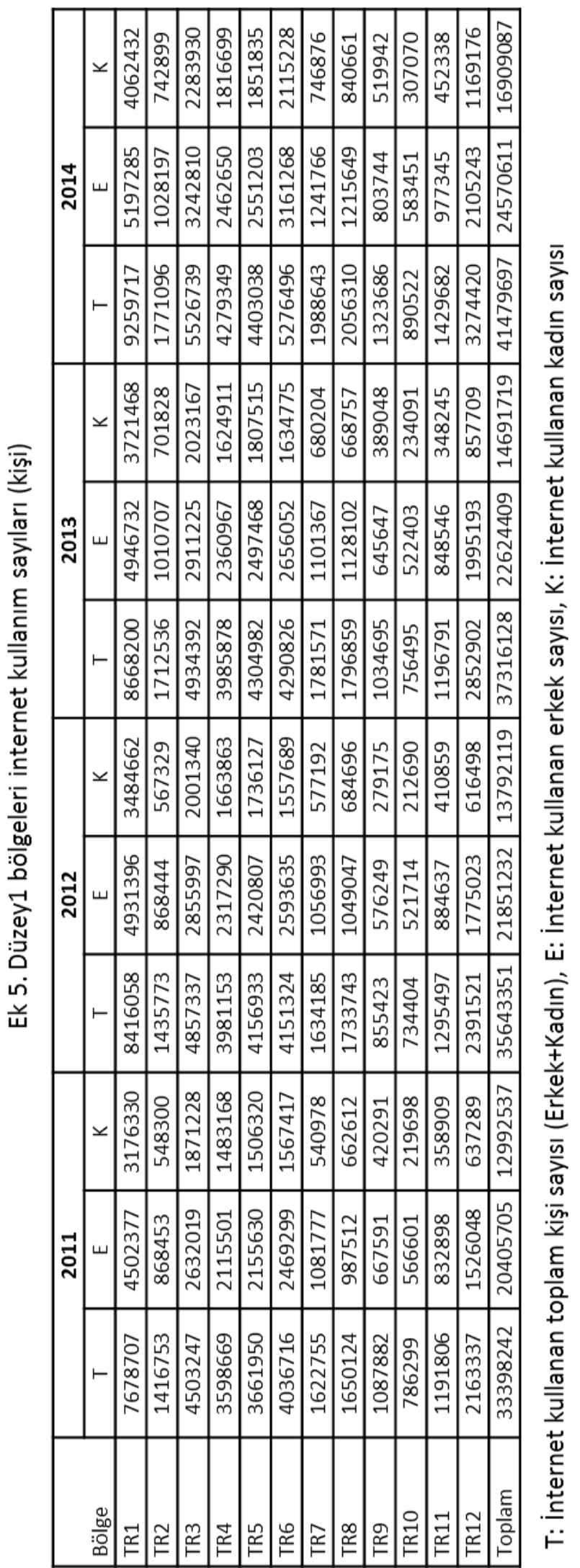

